\title{
Debates in Teaching Bioethics
}

\author{
Katerina Kedraka $^{1, *} \&$ Yiannis Kourkoutas ${ }^{1}$ \\ ${ }^{1}$ Department of Molecular Biology and Genetics, Democritus University of Thrace, Alexandroupolis, Greece \\ *Correspondence: Department of Molecular Biology and Genetics, Democritus University of Thrace, \\ Alexandroupolis, Greece. Tel: 30-697-209-0997. E-mail: kateked@otenet.gr
}

Received: January 25, 2018

Accepted: February 1, 2018 Online Published: February 7, 2018

doi:10.5430/jct.v7n1p32

URL: https://doi.org/10.5430/jct.v7n1p32

\begin{abstract}
In this small scale study in higher education, a good educational practice on the teaching of Bioethics based on transformative learning and accomplished by debates is presented. The research was carried out in June 2016 at the Department of Molecular Biology and Genetics, Democritus University of Thrace, Greece and it includes the assessment of the debating experience by the students participating in the course. The research followed the qualitative method and data was collected by free association through a single question posed to students, asking them to critically reflect on their debating experience. Content analysis was used for analyzing their responses. Debates seem to be a good practice for teaching Bioethics, since it leads to transformative learning for the future scientists, as it is highlighted by the students' views. They strongly state that they were highly interested and motivated by their participation in debates, an active teaching method that promotes the development of critical thinking, questioning, processing and presentation of scientific data, as well as the improvement of communication and cooperation skills. The most significant finding, though, was the critical reflection that young students reached regarding the subtle, difficult ethical issues of Biosciences.
\end{abstract}

Keywords: debate, good practice, active learning, bioethics, higher education

\section{Introduction}

\subsection{Good Educational Practices}

"Good" and efficient teaching is the goal for every teacher, who is wondering: What do I want my students to learn? How will I teach it? Was my teaching good? Were my goals accomplished? The term "good practice" in education is used to describe the teaching actions that aim in improving the learning and educational procedures, as well as the relationships that are developed between the students and the teachers. Actions that are proved to be successful and efficient or even can be used as an example for a specific teaching goal after an evaluation process can be considered as a "good practice".

Although the term has been used by various international institutions, there is no commonly accepted definition for good practice yet, since The European Commission and national authorities have not set any commonly agreed criteria. Good practice refers to "approaches that work well and can be repeated elsewhere"(Note 1). It is also essential to mention that good practices aim at publicity, in order to be available in the educational community, therefore to become a model for other teachers and educational institutions, and to be incorporated in new situations. Another important criterion for the identification of a good practice is innovation. Innovative actions in education are considered the novel, creative and participatory actions that contain and promote new perceptions for education in mainly three dimensions: in the alteration of principles and believes, in the introduction of new pedagogical practices and in the use of new educational pores.

Good educational practices are related to critical learning by setting the following goals(Note 2), although it is not expected all to be fulfilled in every teaching (Martin \& Dowson, 2009):

- Horizontal skills are encouraged emphasizing in critical thinking and in creativity, through various teaching techniques aiming at distributing chances for learning to everybody.

- Creative and attractive actions are carried out in order to motivate students. 
- The suitable supervisory tools and new technologies are selected, but at the same time possible exaggerations are avoided.

- An "educational contract" is set, with clear rules and instructions aiming at the development of mutual respect, promotion of teamwork and strengthening of trainees' self-esteem, mainly through their motivation to take on their responsibility for their learning.

- The performance of students is assessed, but also feedback on their work is provided and feedback questions are encouraged, mostly when they lead to critical questions: What did I actually learn? How did I work? Which sources did I use? Which were my restrictions? What could I have done differently? How did I manage to overcome the difficulties I met? etc.

However, "good teaching practices" have been criticized within the education community, due to subjective assessment. For example, it is not clear whether a good teaching practice could be transferred subjectively in another teaching framework. Or which elements constitute a "good practice", who will decide, based on which criteria? It is noteworthy, though, to mention that the use of a "good educational practice" does not mean that we should abandon the traditional teaching strategies, especially when they lead to obviously positive results, but still "good practices" provide several teaching choices.

\subsection{Modern Theories for Transformative and Active Learning}

It becomes obvious that the term "good educational practices" is associated with modern learning theories and innovative teaching methods. An interesting debate has been initiated regarding the importance of critical thinking in learning (Cranton, 2006) and the communicative and emancipatory dimension of learning instead of instrumental learning in higher education (Alhadeff-Jones, 2011). The theory of Transformative Learning, introduced by the American thinker Jack Mezirow (1991), incorporates different types of knowledge(Note 3): (1) the instrumental knowledge, the traditional means for obtaining knowledge in the educational programs, (2) the communicative knowledge, concerning the understanding of ourselves, of others, taking into account the norms of the culture, community or society in which we live, and (3) the emancipatory knowledge, a product of critical thinking leading to self-awareness and to the right use of scientific, as well as of broader knowledge we gain as individuals. The theory of Transformative Knowledge focuses exactly on the above points, since "it tries to explain the way that the adult knowledge is constructed and to determine the processes according to which the frameworks based on which we understand and interpret our experiences are transformed" (Mezirow, 1991: XII).

For Mezirow (2007the main issue in learning is the critical feedback of beliefs, principles and views of the trainees, in order to form a more viable figure of the world and their position in the world (Kokkos, 2011). The process through which the questioning of established beliefs and views is performed constitutes the critical thinking that may help the adults in examining critically the logic basis of their interpretation and form "a new reformed interpretation of their experiences as a guide for empathy and action" (Mezirow, 1991: 35). Thus, learning - especially when addressed to students - should target (except of knowledge acquiring/gathering) in characteristics, such as "open mind", will for learning, mood for change, analytical and complex thinking, creativity, innovation, inventiveness, ability for group work and activeness and for this reason critical thinking should be encouraged in educational programs in the Universities (Stanovich \& Stanovich, 2010).

As an evolution of Transformative Learning, Knud Illeris, one of the most important modern theoretical teaching scientists, proposes the approach of Holistic Learning, both in school and in higher education. According to Illeris, learning depends on three interactive dimensions (Kokkos, 2016):

Context: The context includes the knowledge, the skills, as well as the attitude, the behavior and the values that are acquired through the learning procedure. It also includes the educational methods and practices that are used. Moreover, Illeris also includes the concern on the critical feedback of disorienting dilemmas in the context of learning, in other words he emphasizes the Transformative Learning.

Instigation and Relationships between Educator and Trainees: This dimension refers to the emotional implication of the trainees during the learning process and especially to the relationships with the educators, as well as to the elements of incitement, motivation, interest development and mood and commitment for knowledge.

Environment: It is about the framework within the learning process takes place. It includes both the direct framework, meaning the educational institution, and the wider social framework.

Holistic Learning, according to Illeris (2007), is performed when every one of the above dimensions functions ideally, but interacts organically with the other dimensions as well. Instruction is planned by the educator based on 
his personal theory for education, learning and articulation of scientific knowledge, initiatives, innovations and creative ideas that he brings to this teaching.

\subsection{Debate as a Good Educational Practice in Higher Education}

Quality instruction is a strong motivating factor in higher education (Sogunro, 2017), linked to critical thinking, problem solving, communication, acquiring of presentation skills and team working (Roy \& Macchiette, 2005). Cranton (2002) reported that critical thinking should become a clear target of all forms of education and mainly of the adults, since by this way the students become open minded in new ways of thinking. However, Bissell and Lemons (2006) noted that higher education do not always encourage the students to think critically. Literature review shows that the debate as an educational technique is considered to significantly contribute to the development of equivalent skills. Walker and Warhust (2000) argued that the use of debates in the educational process is effective for the development of critical thinking and strengthens analytical problem solving, communication, presentation skills, group forming and cooperation skills, as well as critical approaches of the subject of the course. Brown (2015) argues that the use of debates as an in-class teaching strategy improves students' critical thinking and collaborative learning skills. Moeller (1985) realized that although many trainees are initially concerned regarding the procedure of the debate, the technique was proven to be valuable and helped them in developing critical thinking skills. Goodwin (2003), who also used the debate as a teaching method, asked the opinion of the students on the process he followed and he reported that many students commented the lack of familiarization with this method and that sometimes they felt awkward. The majority of the students, however, responded positively, noting that the debate helped them in acquiring in-depth knowledge and in familiarization with the arguments' quest, analysis and presentation. The debate helped them to come across and face different views and to improve their critical thinking.

Professors use often the debate in order to increase the active participation of the students, especially in the field of Human and Social Sciences and selectively in the field of Natural Sciences or Technology (Jugdev, Markowski, \& Mengel, 2004). Proulx (2004) used the debates in the field of Biosciences for the analysis, control and assessment of arguments and the results of his research showed that the technique helps the students to investigate critically biological issues that influence the society. Vo and Morris (2006) discovered that the debates used during their teaching increased the benefits of the traditional lecturing, due to the active and creative participation of the students. In addition, Osborne (2005) realized that this technique helps the students to learn discipline and strengthened their ability to approach knowledge with critical and moral spirit. He also argued that the ability to focus and present valid and convincing arguments contributes positively to the preparation of their future carrier. Dickson (2004) reports that, through the debate, the ability of the students to work in groups and to analyze the arguments is enhanced, improving by this way their ability to think critically. Team working may lead to higher levels of thinking, involving analysis, synthesis, and evaluation through the use of convincing evidence that they have to present and provides them the chance to participate actively in the process of learning, therefore critical thinking is achieved (Gokhale, 1995).

The debates may take many forms. The most common kind of debate is in a class when there is the option for two trainees or two groups to develop opposite opinions for a certain issue (Tumposky, 2004). The traditional process of the debates begins with the choice of the topic, which leads the two groups either to defend it or to oppose against it; in other words, the one group supports the one aspect and the other group is opposed to it. However, in the debate, success does not mean victory, but the degree of interest and motivation achieved by each group. Roy and Macchiette (2005) highlighted particularly the importance of the assessment and the feedback processes for the successful application of the debate technique.

Darby (2007) argued on the benefits arising from the use of debates in teaching: the development of critical and analytical thinking, strengthening at the same time group working and communication. He believes that it is an effective educational tool that increases the responsibility for learning and the active participation required by all participants. Moreover, it provides an experience through which the students can develop research abilities on current issues, become capable in preparing rational arguments, learn to differentiate between subjective and well-documented information, to express their aspects and pose question based on evidence and to listen actively different opinions, as Kennedy (2007) noted. The most important, however, advantage of the method, as highlighted by Darby (2007), is that the students reported that the experience of the debate is amusing and that they really have a great time working!

1.4 Debates in Teaching Bioethics in the Department of Molecular Biology and Genetics, Democritus University of Thrace

The module "Bioethics" is an elective course in the curriculum of the Department of Molecular Biology and Genetics (DMBG), Democritus University of Thrace (DUTH) in Greece. In the frame of the course, several topics 
relative to the ethical development of Bioscientists associated with their role as scientists and researchers in the modern scientific world are set. The goal is the development of critical scientific thinking and analysis of complex scientific and social problems that arise from the biotechnological evolution in the frame of a responsible and ethical approach in the field of Biosciences.

McGonigal (2007) noted that educators in any field may use the theory of Transformative Learning, so the two professors who were assigned the co-teaching of Bioethics decided to base their approach on Transformative Learning Theory, as it was considered suitable for the development of critical thinking on ethical issues in the field of Biosciences.

The course was structured in four major chapters:

\section{Chapter 1: Introduction to Bioethics}

Basic principles of bioethics

Issues of scientific development and management of ethical dilemmas in the modern scientific environment

Chapter 2: The legal framework

The legal framework in Greece - directives and legislation

The legal framework in Europe - directives and legislation

Bioethics and International forums

Chapter 3: Modern issues of Bioethics in Molecular Biosciences

- Designer babies

- DNA banks

- Genetic modification and agricultural activity

- Human genome and associated challenges

Chapter 4: The role of the Bioscientist

Ethical dimension of the role of the Bioscientist

Professional ethics in Biosciences

The topics of the 3rd Chapter mentioned above, along with the proposed references were announced to the students, who chose their partners and formed groups of three and then they selected the topic that they wanted to work on, as well as the negative or positive aspect to support. The process of the debates included the stages below:

- 10 min presentation of the aspect of each group, based on scientific data and arguments

- 5 min development of arguments in response to the points that the opposed group has posed

- 3 min for concluding remarks of each group.

Subsequently, all students and trainers voted for the most convincing aspect and the lesson was completed with an extensive and open discussion on each topic.

\section{Methodology}

The present study is a small scale study that was focused on the students' debate experience. The methodology of the research followed the qualitative approach, because it was considered the most appropriate for the in-depth penetration in the students' opinions. The research question was: What would the students consider as significant regarding this specific learning experience? Data was collected in June 2016, by the free, associative recording of the students' opinions, that allowed the respondents to report what was worth highlighting, the "truth" that they wanted to mention by answering the open question: "How would I describe my experience from my participation in the debate?". This technique, because it is anonymous, free and open, ensures that the original experiences and feelings will be deposited (Atkinson, 1998). It is noted that from the 24 students who followed the course of "Bioethics" during the academic year 2015-16, 19 students responded and thus, constituted the sample of the research.

Data was processed by the Content Analysis method, which, using the data categorization process and classification into thematic categories with a clear conceptual definition, allows the contents of the narrations to be translated into findings, which are then interpreted and discussed in qualitative terms. Content Analysis is considered appropriate 
for "decoding and interpreting written data and especially personal beliefs, attitudes, assumptions and perspectives" (Verma \& Mallick, 2004: 224). The analysis process included data interpretation by the researchers, which is the most interesting and provoking - at the same time - part of data processing in qualitative research (Kyriazi, 2006). The views of all students who participated in the survey were used.

The five categories of data that occurred were:

- interesting learning experience

- skills acquired

- co-operation and teamwork

- active learning

- development of critical thinking and transformation of assumptions

\subsection{Study Constraints}

It should be noted, however, that since this is a small-scale study and the qualitative analysis is based on the description and discussion of the views of the particular students questioned, this research does not lead to the generalization of its findings. Therefore, generalization of the findings is not supported in any way, but the essential aspects regarding the educational process of a debate and the experience gained by the students of the Department of Molecular Biology and Genetics is highlighted.

\section{Findings}

The students' answers showed how interesting the learning experience of integrating debates into the "Bioethics" course has been for them. They noted that debates have been an unprecedented, significant and distinct learning experience, with multidimensional components:

My participation in the debate, was absolutely positive. It has been a very important and original life experience.

Very nice experience and I'm glad I had the opportunity to attend this course before I finish my studies.

It was an interesting, pleasant and creative experience. Although pilot, the course was 'smooth' and efficient.

My experience in the debate was something special.

Initially, I would describe my experience in the debate as unique, since there has not been anything like that in any other course.

My participation in the course of Bioethics was a very special experience, mainly due to the teaching methods. The use of debates was undoubtedly unprecedented for all of us. When I applied for the course, I could not imagine how terrific experience it would be.

I think my participation in the debate was a very good experience, because I did not have the opportunity to take part in anything similar before.

Indeed, I was impressed by the excellence of the students' presentations, who supported their topics and the good work and research accomplished was obvious, based on the latest scientific facts.

I will be absolutely honest. The teachers were there for us (believe me they are not all like that!), the course was interesting (VERY) and not boring at all.

Many students focused on the skills they acquired as a very important element of this educational experience:

It contributes to the development of other skills beyond scientific knowledge (e.g. speech readiness, argumentation).

Personally, it has given me the opportunity to develop skills that I could not develop tthrough the other courses, mainly soft skills, which is well known that we will need in the future.

We worked as much as we could on the topic we had been assigned and focused on both the techniques used in debates and the scientific part (scientific presentation of the aspect and readiness to answer in potential "attacks"). 
Through the debate, I mainly managed to get experience of what is like to debate in front of an audience (most important, especially in our science).

Not only we had to acquire the knowledge about the topic we had to defend, but mainly to assimilate and "filter" it, so that we can cope with any arguments that the opposing team would put forward.

It was indeed a very enjoyable and productive process and what I mainly gained, beyond knowledge, was the ability to respond quickly to a question within a friendly and safe climate.

Personally, it was the first time I participated in a similar activity and I think I have been left with new knowledge, skills in argumentation and a lot of questions.

Some, in fact, focused on the co-operation and teamwork they had to display, in order to organize their work:

Initially, there was trust and excellent cooperation among my team members. The way in which the arguments and concerns were presented was also a challenge while working in a team, but also a lesson of respect for those who may have the opposite view.

I worked with people I had never worked before, and with their help we managed to reach teamwork.

I think that our participation in the debates and discussions that followed brought us all a little closer, giving us the opportunity to meet students we didn't know.

The most appreciated element was the energetic way of learning promoted through the course, instead of traditional lectures:

Information collection on the topic, the organization of data and the confrontation with the "rival" group offered an environment for arguments' exchange, something that I haven't experienced in the past. For this reason, I believe the whole experience was excellent and I would definitely repeat it if I had the chance.

Knowledge was not simply provided by the professors, but we went deep into the essence of it. This is the reason why I consider the debate very educative and effective for this course. In addition, by listening to other groups, we consolidated the information much better than in the form of a simple lecture and we were able to form our own opinion on the topics presented.

The experience was exciting. We worked at regular meetings with my colleagues and we had a lot of fun, because we discovered each time new arguments, keeping us alert concerning our data research.

It "forces" you to get deeper into the topic you have to defend, and it proves challenging if you have to defend the opposite view from what you actually believe. Therefore, I think it is better the course is taught this way, rather than providing theoretical knowledge on Bioethics.

The debate was a very nice experience, but mostly a very efficient way of learning.

Totally different teaching method. Very good experience, especially taking into account the theoretical courses we have to follow as students.

I did not have the chance to participate in something like this before and it helped me a lot to get prepared for similar situations that will logically arise in the future in my work. Also, the fact that the course was interactive automatically increased its value and my will to attend it.

The experience of the specific course was quite different from what I have seen so far.... Certainly, this course was not only based on information transmission, like teaching in an amphitheater.

Indeed, even after the debates, I often felt the need to approach deeper some topics, due to the high interest originated from the original, lively and energetic process of the debate.

I think that the choice to offer the course in the form of debates was interesting; it was something we had not been experienced in another course.

Finally, the debates helped the students see that there is not a single answer to ethical issues in the field of Biosciences, but they have to develop their own critical thinking and maybe transform their opinions and assumptions: 
The initiative undertaken by our Professors, Mrs. Kedraka and Mr. Kourkoutas led to an exciting course and in collaboration with the students we acquired experiences, a way of critical thinking on ethical issues that concern the scientific community.

There are issues that do not have clear answers, and it might be difficult to be presented by a professor without any biased attitude in favour of his views. In this way, everyone was given the opportunity to form his/her own opinion on each topic (as much as possible...).

All these debates left me with the impression that we, as Bioscientists, need more training on values and ethics. This course offered many opportunities for thinking and concern, and this is very important for a young person who is entering the adult world.

It helped me understand that there may be different perspectives on a topic, without being able to conclude which is 'correct'. In fact, a healthy confrontation of different opinions was promoted, followed by a fruitful dialogue that contributed to the development of interesting concerns - without conclusions though...

I realized that there is not a one and only "truth" from a scientific point of view or from a moral standpoint.

Of particular interest was the fact that in the search for arguments and counter-arguments, I have often come to a dilemma, without finally being able to end up in favor of "yes" or "no" in absolute terms.

The debate process is very interesting, because it gives you the opportunity to rethink on your views or prejudices.

The idea of the debate was very original and constructive to my opinion. During this last semester of my studies, this process was a great asset, because we had never had the opportunity to think deeper or discuss as adults on specific issues that would probably concern us in our career.

\section{Discussion}

In Greek higher education lecture remains the most common teaching tool and only recently initiatives have been taken, in order to enrich university teaching with modern, interactive methods, so courses are more interesting and attractive for students (Kedraka \& Rotidi, 2017a), although experts on the field underline the importance of bringing in learning the critical thinking and the use of active teaching methodologies (Kokkos, 2016). The views of the students of DMBG showed that the technique of debates applied in the Bioethics course was fully and positively accepted. The students literally "grabbed" the opportunity to develop their analysis and presentation skills, as well as scientific argumentation on several key topics in the field of Biosciences. Thus, they used their critical thinking, confirming the findings of Goodwin (2003) and Scott (2008), who concluded that students acquire not only knowledge, but critical thinking skills through debates. Likewise, Walker and Warhust (2000) found in their study that classroom debates increased critical thinking, as they enhanced analytical problem solving, communication, presentation, and ability to form groups, while as Moeller (1985) underlined, the whole debating process proved valuable and helped students to increase their critical thinking skills. In our study, we can also distinguish the role of team work in relation to academic motivation, commitment, and achievement, as students emphasized that through the debates not only did they learn, but they also collaborated and enjoyed their effort, confirming Martin and Dowson (2009), who argued that the achievement of academic goals could be perceived in relational terms, as well.

Koulaouzides (2014) argued that there is not learning without some kind of transformation; therefore, it seems that the Transforming Learning theory, as proposed by Mezirow (1991, 2007), can be applied in teaching Bioethics using debates, since students seem to have reached some kind of critical thinking concerning their interpretation, understanding and concern on ethical issues. In addition, the use of debates met the holistic view of learning that Illeris (2007) suggests: as a combination of content learning, incorporating knowledge and skills, as well as the quests concerning the critical reassessment of their stereotypical assumptions and beliefs. The second component Illeris proposes, incitement and communication, was also involved, because the emotional involvement of students during the learning process, as well as the development of interest, mood and motivation commitment to learning were achieved. All the above were accomplished within the appropriate and safe educational environment - the DMBG. 
What did the students of the DMBG finally earn out of their experience in debates? They had the opportunity to test their strengths, to learn more about contemporary ethical issues of their scientific field, to think and plan their arguments and evaluate their ideas, rhetoric and persuasion skills. They learned to collaborate with their fellow students and developed team bonds. They gained knowledge, they have enjoyed their work during this course and they emphasized that their active involvement was far more interesting than the typical teaching methods - that is lecturing. The debate offered them an active learning experience, simply because they participated in the learning process! It is obvious that the debate experience, led to empirical learning via active participation, a process that gave them the chance to reach knowledge through questioning and reflection (Brookfield, 2012) and offered them a deeper understanding of the modern, moral conflicts in the field of Biosciences and Biotechnology. Kedraka and Rotidi (2017b) highlighted the importance of the development of critical thinking for a Science student - a Bioscientist to be - in order to be able to question his assumptions, make ethical justifications and make decisions with respect to complicated bioethical dilemmas. Therefore, it seems, that this, small scale research conducted in Greek higher education revealed the importance of a "bio-scientific ethos", which can be developed through appropriate educational practices, in order to prepare future scientists to deeply understand and respect the human being, the current scientific, socio-political and cultural requirements and commitments, and finally, approach them critically, based on a rational and yet humanitarian orientation.

\section{Conclusion}

We can conclude that using the debate, an excellent learning tool (Christudason, 2003), in the teaching of Bioethics was a good educational practice, since it motivated students and "motivated students are the end result" of higher education, as Wiseman and Hunt (2001:10) underlined. However, it is clear that further research is needed on the use of debates and other teaching methods leading to transformative learning, in order to draw safe conclusions for the education of bioscientists, since it is essential that scientists should be able to critically address ethical scientific challenges at a professional and social level.

We thought it would be interesting to conclude by quoting a student's statement:

I believe it is a course that every student should attend, because through this experience, he would develop his critical capacity and think beyond Science - as a Human Being.

\section{Acknowledgements}

We would like to thank our students of the Department of Molecular Biology \& Genetics-Democritus University of Thrace, Greece, who willingly took part in this small scale study, by depositing their views concerning their debating experience within the course "Bioethics" during the second term of the academic year 2015-16.

\section{References}

Alhadeff-Jones, M. (2011). Transformative learning, Life Stories and Chronical Dimensions of Learning, Adult Education, 22, 13-22.

Atkinson, R. (1998). The life story interview. Sage University Papers on Qualitative Research Methods. Thousand Oaks, CA: Sage. https://doi.org/10.4135/9781412986205

Brookfield, S. (2012). Teaching for Critical Thinking: Tools and Techniques to Help Students Question Their Assumptions. San Francisco, CA: Jossey-Bass.

Brown, Z. (2015). The use of in-class debates as a teaching strategy in increasing students' critical thinking and collaborative learning skills in higher education, Educationalfutures, 7(1), 39-55. http://educationstudies.org.uk/wp-content/uploads/2015/01/Brown.pdf

Christudason, A. (2003). The Debate as a Learning Tool. Retrieved from http://www.cdtl.nus.edu.sg/success/sl11.htm

Cranton, P. (2002). Teaching for Transformation. New Directions for Adult and Continuing Education, 93, 63-71. https://doi.org/10.1002/ace.50

Cranton, P. (2006). Understanding and Promoting Transformative Learning. San Francisco: Jossey - Bass.

Darby, M. (2007). Debate: a teaching-learning strategy for developing competence in communication and critical thinking. Journal of Dental Hygiene, 81(4), 78. http://www.ncbi.nlm.nih.gov/pubmed/18173892 
Dickson, R. (2004). Developing "Real-world intelligence": Teaching argumentative writing through debate. English Journal, 94(1), 34-40. https://doi.org/10.2307/4128845

Gokhale, A.A. (1995). Collaborative Learning Enhances Critical Thinking. Journal of Technology Education, 7(1). https://doi.org/10.21061/jte.v7i1.a.2

Habermas, J. (1971). Knowledge and Human Interests. Boston: Beacon Press.

Hellenic Ministry of Education, (2010). The new school. Athens. (in Greek).

Illeris, K. (2007). How We Learn: Learning and Non-learning in School and Beyond. London: Routledge.

Jugdev, K., Markowski, C., \& Mengel, T. (2004). Using the debate as a teaching tool in the online classroom. Online Cl@ssroom, 1(10), 4-6.

Kedraka, K., \& Rotidi, G. (2017a). University Pedagogy: A New Culture is Emerging in Greek Higher Education. International Journal of Higher Education, 6(3), 147-153. https://doi.org/10.5430/ijhe.v6n3p147

Kedraka, K., \& Rotidi, G. (2017b). Bioscience and Bioethics highlighted by adult education's socio-cultural approach of P. Jarvis and person-cantered theory of C. Rogers for the education of the Bioscientist as a "person". Educational Circle, 5(1), 48-68. http://www.educircle.gr. (in Greek).

Kennedy, R. (2007). In-class debates: Fertile ground for active learning and the cultivation of critical thinking and oral communication skills. International Journal of Teaching and Learning in Higher Education, 19(2), 183-190.

Kokkos, A. (2011). Transformative learning in Europe: A Review in Theoretical Approaches. Adult Education, 22, 5-12. (in Greek).

Kokkos, A. (2016). Towards a multi-dimensional way of learning in Higher Education. In K. Kedraka (Ed), Proceedings of the Symposium on University Pedagogy: Education and training in Higher Education, a terra incognita; (pp 38-52). Alexandroupolis: Democritus University of Thrace. (in Greek)

Koulaouzides, G. (2014). Learning and transformation: are we not transformed a little, every time we learn? In D. Andritsakou, and L. West (Eds.), What's the point of Transformative Learning? Proceedings of the 1st Conference of ESREA's Network "Interrogating Transformative Processes in Learning and Education: An International Dialoque” (pp 43-49). 27-29/06/2014, Athens, Greece: ESREA \& Hellenic Adult Education Association.

Martin, J. A., \& Dowson, M. (2009). Interpersonal Relationships, Motivation, Engagement, and Achievement: Yields for Theory, Current Issues, and Educational Practice. Review Of Educational Research, 79(1), 327-365. https://doi.org/10.3102/0034654308325583

McGonigal, K. (2007). Teaching for transformation: From learning theory to didactical strategies. Adult Education, $12,12-15$.

Mezirow, J. (1991). Transformative Directions of Adult Learning. San Francisco: Jossey-Bass.

Mezirow, J. (2009). An Overview on Transformative Learning. In K. Illeris, (Ed.), Contemporary Theories of Learning (pp 90-105). London and New York: Routledge,.

Mezirow, J., \& Associates, (2007). Transformative learning. Athens: Metehmio. (in Greek).

Osborne, A. (2005). Debate and student development in the history classroom. New Directions for Teaching and Learning, 103, 39-50. https://doi.org/10.1002/t1.202

Proulx, G. (2004). Integrating scientific method and critical thinking in classroom debates on environmental issues. The American Biology $\quad$ Teacher, 66-33. https://doi.org/10.1662/0002-7685(2004)066[0026:ISMCTI]2.0.CO;2

Scott, S. (2008). Perceptions of Students' Learning Critical Thinking through Debate in a Technology Classroom: A Case Study. The Journal of technology Studies, 34(1), a.5. https://doi.org/10.21061/jots.v34il.a.5

Sogunro, A.O. (2017). Quality Instruction as a Motivating Factor in Higher Education, International Journal of Higher Education, 6(4), 173-184. https://doi.org/10.5430/ijhe.v6n4p173

Stanovich, K.E., \& Stanovich, P.J. (2010). A framework for critical thinking, rational thinking, and intelligence. In D. Preiss and R. J. Sternberg (Eds.), Innovations in educational psychology: Perspectives on learning, teaching and human development (pp 195-237). New York: Springer. 
Tumposky, N. (2004). The debate debate. Clearing House, 78(2), 52-55. https://doi.org/10.3200/TCHS.78.2.52-56.

Verma, G., \& Mallick, K. (2004). Educational research. Athens: Tipothito. (in Greek).

Vo, H.X., \& Morris, R.L. (2006). Debate as a tool in teaching economics: Rationale, technique, and some evidence. Journal of Education for Business, 81(6), 315-320. http://dx.doi.org/10.3200/JOEB.81.6.315-320

Walker, M., \& Warhurst, C. (2000). "In most classes you sit around very quietly at a table and get lectured at...": Debates, assessment and student learning. Teaching in Higher Education, 5(1), 33-49. https://doi.org/10.1080/135625100114948

Wiseman, D. G., \& Hunt, G. H. (2001). Best practices in motivation and management in the classroom. Springfield, IL: Charles Thomas.

\section{Notes}

Note 1. http://socialactivism.gr/index.php/kales-praktikes/358-kales-praktikes-orismos-antikeimeno-methodos

Note 2. as stated in the principles of Greater Educational Training that aimed in the awareness of teachers and their preparation concerning the philosophy and the practice of a "New School" (see. Hellenic Ministry of Education, 2010),

Note 3. also described by Habermas (1971) 